\title{
How can medicine close its gender pay gap?
}

\author{
Cite as: CMAJ 2021 April 12;193:E528-9. doi: 10.1503/cmaj.1095933
}

Posted on cmajnews.com on March 26, 2021

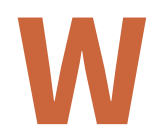

omen account for half of all doctors and medical trainees in Canada, but too often in medicine, that's where gender equality ends. Studies show female physicians earn less, advance slower and face higher risks of burnout than their male peers. So, what can the profession do about it?

According to Dr. Clover Hemans, of Ontario Medical Association (OMA) Women, "waiting for voluntary steps to rebalance gender inequities and power does not work."

At a briefing, Hemans presented 10 actions to advance the role of women in medicine in the next 12 months. Her top recommendations: include women from diverse backgrounds on hiring committees and demand transparency in job descriptions and compensation.

While many health care organizations pay lip service to female physicians' contributions, they are seldom transparent about how much they pay women compared to men performing the same roles.

Recent Canadian research shows that salary disclosure laws reduced the gender pay gap in the public sector by about $30 \%$. But medical associations, including the OMA, have tended to resist such "sunshine" laws being applied to physicians.

According to Hemans, it's tough to know how many women hold medical leadership positions in Canada, let alone how many are women of colour, "because we simply do not measure this metric."

Hemans called on health organizations to measure and report numbers of female clinical chiefs of departments, corporate division heads and equally paid leaders. She also called for fair parental leave,

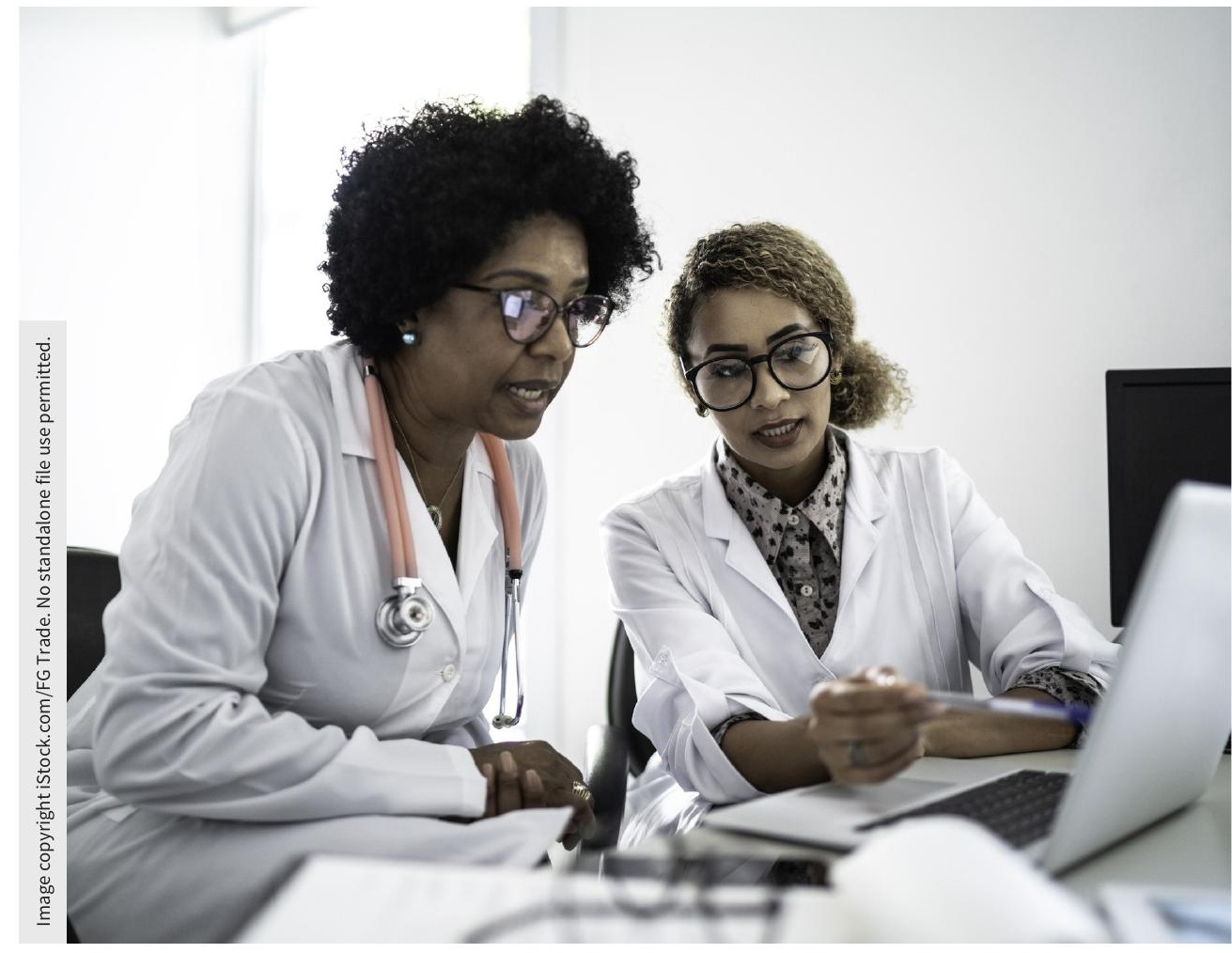

Pay transparency and diverse representation on hiring committees are first steps to levelling the financial playing field in medicine.

mandatory bias training and enforcement of anti-discrimination policies.

Moreover, Hemans urged physicians to continue to resist "pink pointing" women toward some specialties and away from others because of their gender and family situation.

Men are not viewed as less when work and family life collide, nor are they expected to pick up the "second shift" of childcare and household duties, said Hemans. And men interested in competitive programs "often have an implicit advantage through mentorship and informal relationships with senior male leaders."

Hemans said women must elevate and amplify each other in the same way. "We must make ourselves visible and undeniable. We must learn to leverage informal networks, make friends with writers and journalists, be comfortable with writing so we can share our insights and experiences, and learn to brand out work."

Meanwhile, men can make a point of including and mentoring women. "We need allies and sponsors in our male leadership to not be afraid to mentor female trainees," said Dr. Kimberly Lazare. "As trainees and young physicians early in our careers, we need to look not only to female mentors but also to male mentors for those opportunities."

According to OMA president Dr. Samantha Hill, closing the gender pay 
gap will also require modernizing physician fee schedules and payment models. "Patients who are complicated or need more time are often referred to women because the referring doctor knows that woman will take the time," even when that extra time isn't compensated, Hill said.

Fee schedules tend to incentivize quantity of procedures over time spent with patients, which may not reflect what's best for patients, especially as Canada's population ages and becomes more medically complex, according to Hill and Lazare.

"Studies have shown that having more women in health policy leadership enhances the provision of high-quality patient care... and patients of women physicians have higher levels of satisfaction and reduced readmission and mortality rates after being discharged from hospital," Lazare said. "We cannot make progress in this area with respect to gender inequity without capitalizing on and celebrating these contributions of women in medicine."

Diana Duong, CMAJ

Content licence: This is an Open Access article distributed in accordance with the terms of the Creative Commons Attribution (CC BY-NC-ND 4.0) licence, which permits use, distribution and reproduction in any medium, provided that the original publication is properly cited, the use is noncommercial (i.e., research or educational use), and no modifications or adaptations are made. See: https://creativecommons.org/ licenses/by-nc-nd/4.0/ 